\title{
TIDAL POWER PLANT ALONG THE WESTERN SHELDT
}

L.F. Mooyaart, Royal Haskoning, I.mooyaart@royalhaskoning.com

J. Van Duivendijk, TU Delft (retired), hans@vanduivendijk.nl

S.N. Jonkman, Royal Haskoning/TU Delft, b.jonkman@royalhaskoning.com

$$
\text { J.K.Vrijling, TU Delft, j.k.vrijling@tudelft.nl }
$$

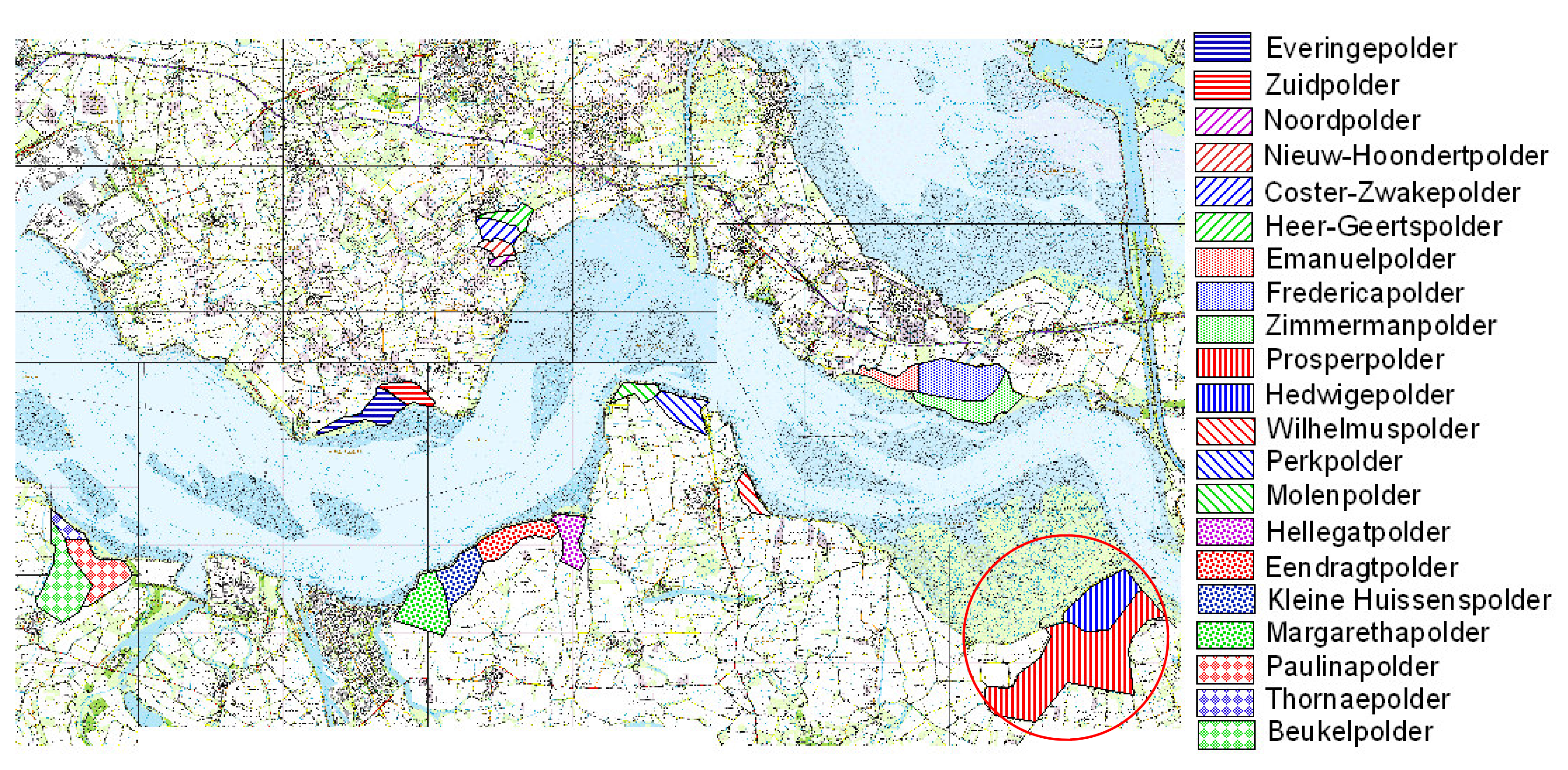

Figure; Analysed (not densely populated) polders for concept of energy polder

\section{INTRODUCTION}

So far tidal energy did not seem feasible for the Netherlands, as the tida difference is relatively small. After research done on a tidal power plant at the Brouwersdam it turned out that production of tidal energy could become attractive when the tidal energy project also leads to benefits for other functions, such as improvement of the ecology of the area.

On the $11^{\text {th }}$ of March 2005 the Netherlands signed an agreement on the Western Scheldt. This agreement stated that the Hertogin Hedwigepolder near the Dutch-Belgian border had to be inundated. The aim of this plan was to compensate nature loss due to deepening of the Western Scheldt for shipping requirements. By combining the government's objective of more energy production from renewable energy sources with came to gain tidal energy from polders.

The aim of this study is to research the economical and technical feasibility of a tidal power plant (TPP) along the Western Scheldt, using a polder as a basin.

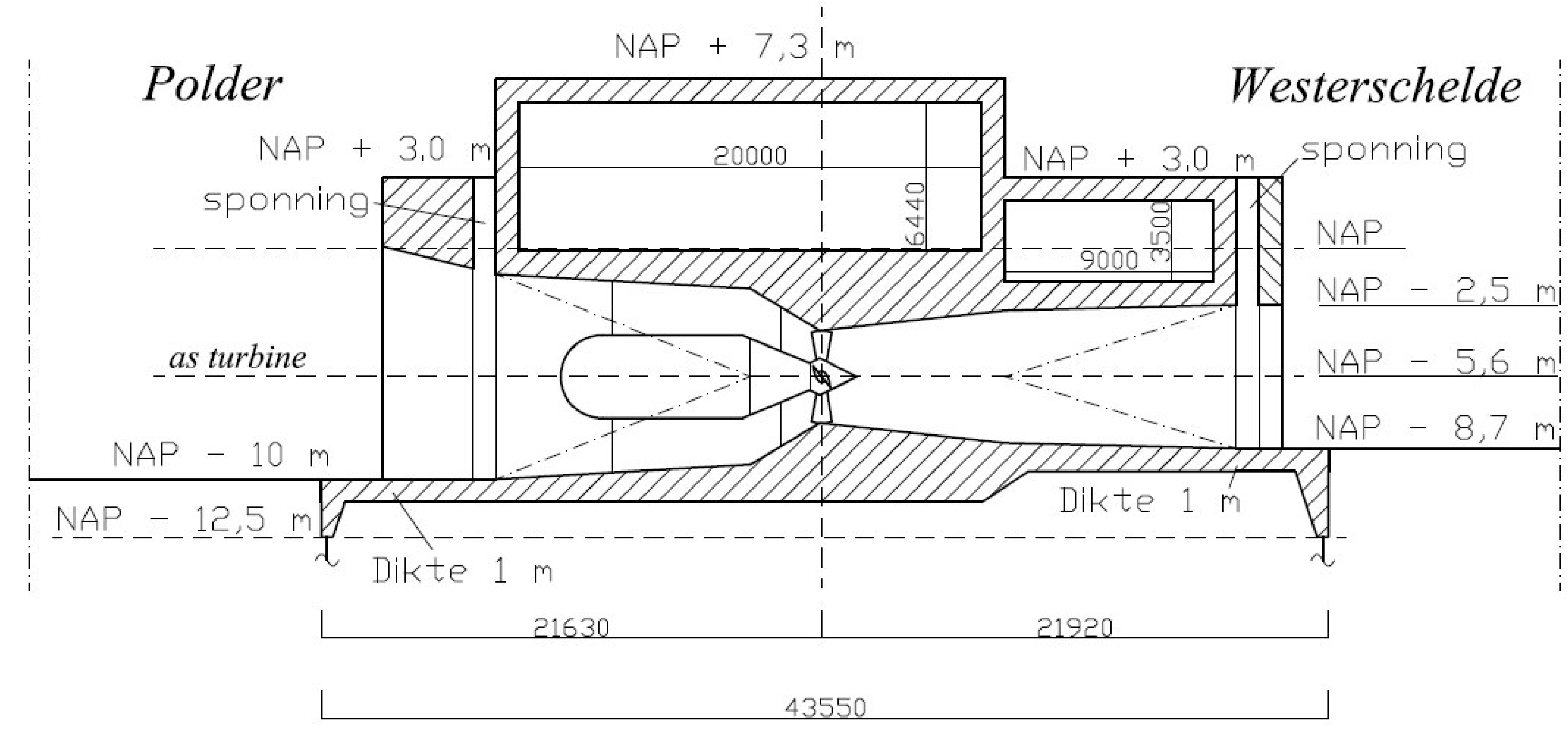

Figure; Cross-section turbine

\section{TIDAL ENERGY SCHEME}

The current primary dike functions as a tidal barrage, creating an impoundment together with old dikes which were used to reclame land about a hundred years ago.

As the tide rises, the estuary basin fills with water. Around the time of high tide, sluices within the barrage are closed, impounding water upstream of the structure and allowing natural drainage downstream of the barrier during the ebbing phase of the tide. When a sufficient difference in water level (or 'head') has been created either side of the barrage, the gates are re-opened to release the impounded water through turbines contaned within the barage to gen

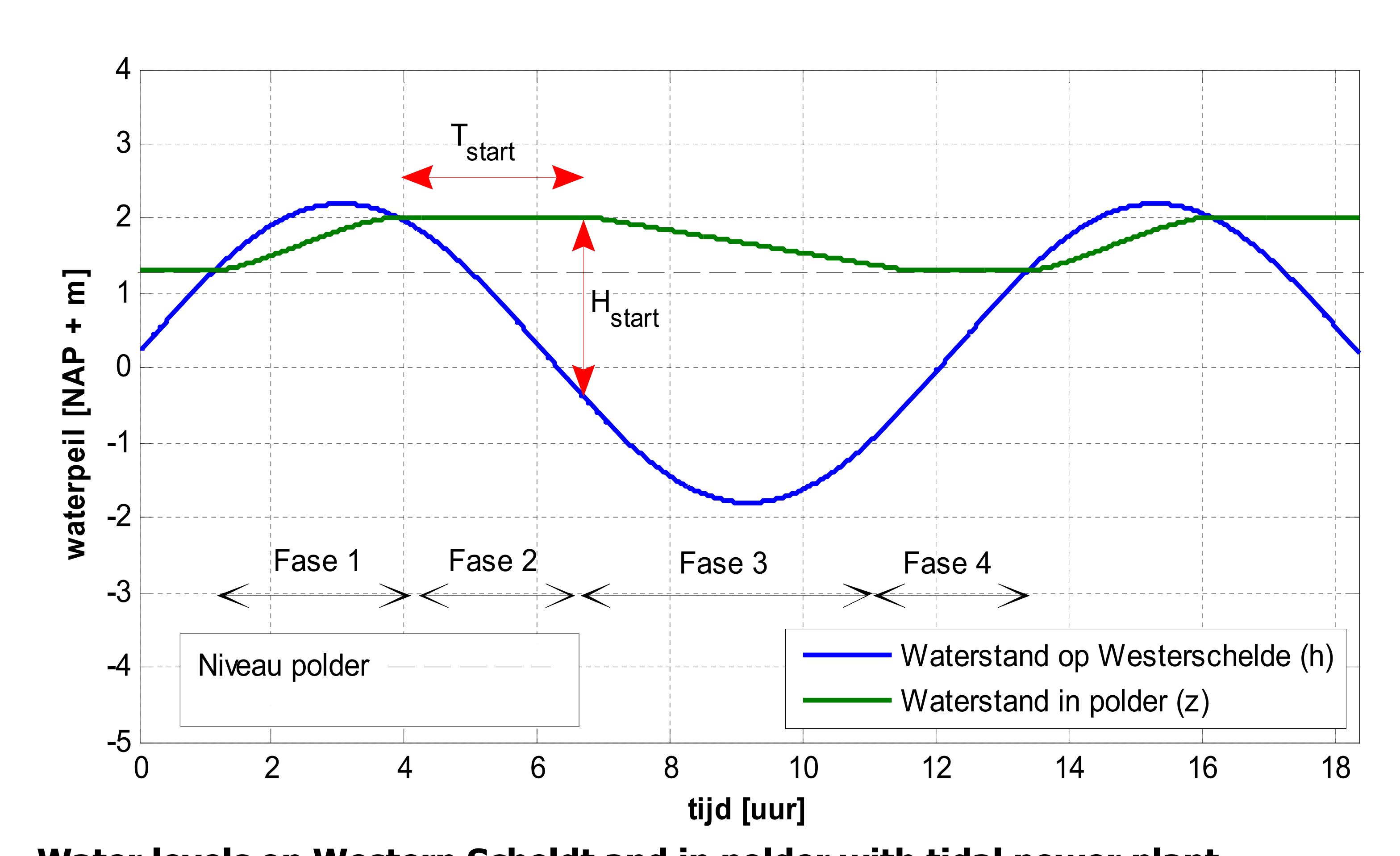

Water levels on Western Scheldt and in polder with tidal power plant

\section{KEY ASPECTS OF TPP AT PROSPER-AND}

\section{HEDWIGEPOLDER}

Possibilities for production of tidal range energy in the aforementioned polders were studied. The main results of this analysis can be summarized as follows:

The average tidal range at the Prosper- and Hertogin Hedwigepolder is 5 meter and is the largest tidal range in the Netherlands.

The elevation of these two polders is relatively high. The level of the Prosperpolder is around 1.5 meter above sea level and the Hertogin

Hedwigepolder is around 1.9 meter above sea level. Because of this relatively high ground level the head during ebb is relatively high compared to the head during flood. Therefore a tidal power plant was chosen which produs ench polder is filled by means of sluices. Bulb-turbines were chosen for this tidal power plant. These turbines can get a high efficiency, are the least fish unfriendly and are used mostly in current tidal power plants and run-of-river plants in the world.

By applying a cost-benefit analysis it was determined that 5 turbines with a diameter of 4 meter and 9 sluices with a width of 30 meter would deliver the cheapest energy.

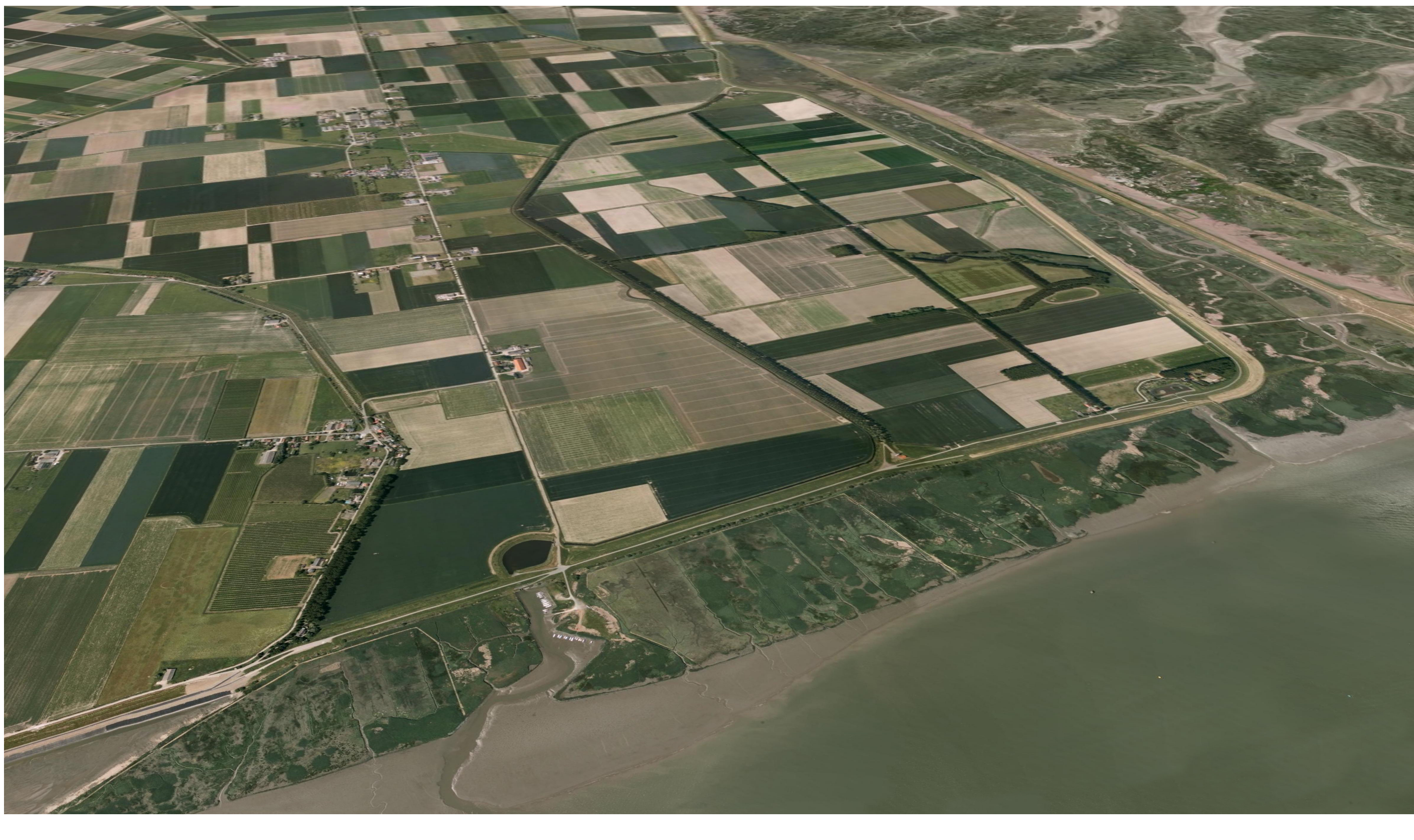

3D View of current situation

\section{CONCLUSIONS}

The following can be concluded concerning the cost and benefits of placing a tidal power plant at the Hertogin Hedwige- and Prosperpolder. This tidal power plant annually produces $64.3 \mathrm{GWh}$ of electricity. The largest part of this will be produced during normal and spring tide. The costs of the tidal power plant were estimated between 79.2 and 86.3 million euro.

An economic model is used to determine the ratio between cost en benefit. The necessary energy price to retrieve invested money back in 20 and in 40 years is determined, including a discount rate of $6 \%$. With this analysis a minimal energy price of $10.8 \mathrm{cent} / \mathrm{kWh}$ and a maximum energy price of $15.5 \mathrm{cent} / \mathrm{kWh}$ were found.

\section{REFERENCES}

Bernshtein (1996) Tidal
velopment Institute. 444.

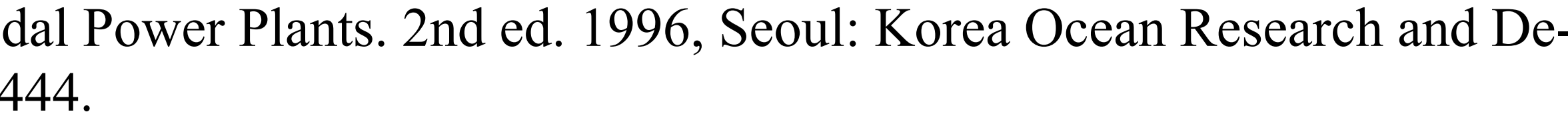
- Gibrat (1996) L'Energie des Marées. 1966, Paris: Presses Universitaires de France. Van Duivendijk (2007) Water Power Engineering, Principles and Characteristics, Lecture No-

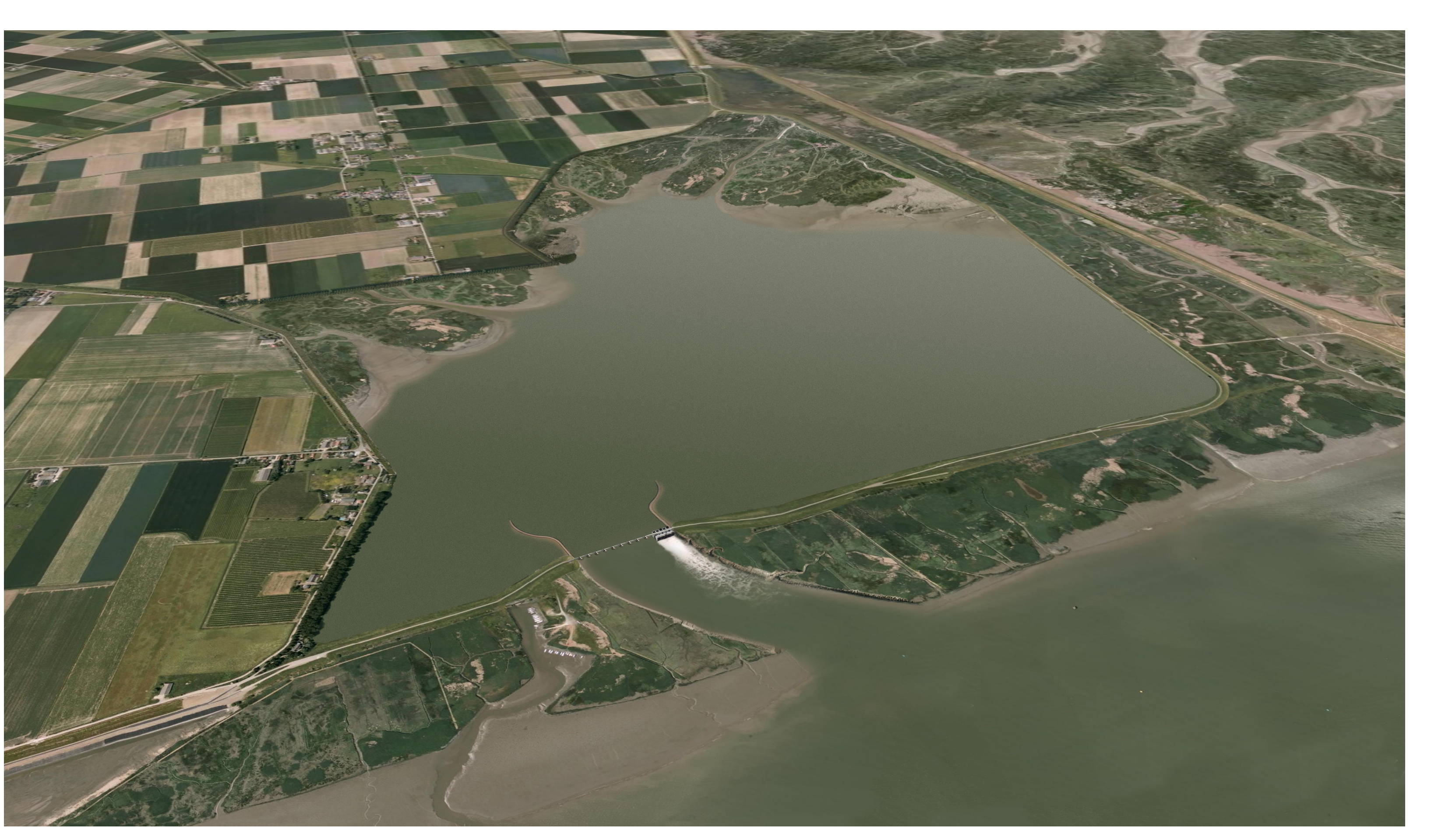

D View of situation with tidal power plant 